\title{
CIENCIAMATRIA
}

Revista Interdisciplinaria de Humanidades, Educación, Ciencia y Tecnología

Año VII. Vol. VII. N¹2. Enero - Junio. 2021

Hecho el depósito de ley: pp201602FA4721

ISSN-L: 2542-3029; ISSN: 2610-802X

Universidad Nacional Experimental Francisco de Miranda (UNEFM). Santa Ana de Coro. Venezuela

Edgar Fernando Arévalo-Jara; Mariella Johanna Jácome-Ortega;

Cristián Andrés Erazo-Álvarez

DOI $10.35381 / \mathrm{cm} . v 7 i 12.439$

\section{La administración del riesgo empresarial en la Cooperativa Alfonso Jaramillo CAJA}

\section{Enterprise Risk Management in the Cooperative Alfonso Jaramillo CAJA}

Edgar Fernando Arévalo-Jara edgar.arevalo@est.ucacue.edu.ec

Universidad Católica de Cuenca, Cuenca

Ecuador

https://orcid.org/0000-0002-2128-7288

Mariella Johanna Jácome-Ortega

mariella.jacome@ucacue.edu.ec

Universidad Católica de Cuenca, Cuenca

Ecuador

https://orcid.org/0000-0002-4552-6378

Cristián Andrés Erazo-Álvarez

cristianerazo@ucacue.edu.ec

Universidad Católica de Cuenca, Cuenca

Ecuador

https://orcid.org/0000-0001-8746-4788

Recibido: 01 de octubre de 2020

Aprobado: 15 de diciembre de 2020 


\title{
RESUMEN
}

Toda entidad a lo largo de su existencia presenta algún tipo de riesgo, estos eventos pueden generar un cierre total de sus operaciones, por ello nace esta investigación, donde se pretende mitigar cada uno de los riesgos presentes accionando la administración con el fin que sus activos y su patrimonio no sean afectados. Metodológicamente es de tipo descriptivo-explicativo. Como resultado se encontró que todos riesgos posibles son importantes para la Cooperativa CAJA, pero más aun los que generen perdidas económicas para ello se implementó la metodología de Hammig como disipador de estrategias correlacionados a identificar, medir, monitorear y controlar todos los ángulos posibles de cada riesgo y llegar a una estrategia óptima, innovando así el ámbito cooperativista de la institución en particular, alcanzando así los objetivos.

Descriptores: Operación administrativa; resolución de problemas; toma de decisiones. (Palabras tomadas del Tesauro UNESCO).

\begin{abstract}
Every entity throughout its existence presents some type of risk, these events can generate a total closure of its operations, for this reason this investigation was born, where it is intended to mitigate each of the present risks by activating the administration in order that its assets and your assets are not affected. Methodologically it is descriptiveexplanatory. As a result, it was found that all possible risks are important for the CAJA Cooperative, but even more those that generate economic losses. For this, the Hammig methodology was implemented as a dissipator of correlated strategies to identify, measure, monitor and control all the possible angles of each risk and arrive at an optimal strategy, thus innovating the cooperative environment of the institution in particular, thus achieving the objectives.
\end{abstract}

Descriptors: Management operations; problem solving; decision making. (Words taken from the UNESCO Thesaurus). 


\section{CIENCIAMATRIA}

Revista Interdisciplinaria de Humanidades, Educación, Ciencia y Tecnología

Año VII. Vol. VII. N¹2. Enero - Junio. 2021

Hecho el depósito de ley: pp201602FA4721

ISSN-L: 2542-3029; ISSN: 2610-802X

Universidad Nacional Experimental Francisco de Miranda (UNEFM). Santa Ana de Coro. Venezuela

Edgar Fernando Arévalo-Jara; Mariella Johanna Jácome-Ortega;

Cristián Andrés Erazo-Álvarez

\section{INTRODUCCIÓN}

A primera vista se considera que al día de hoy toda entidad presenta un riesgo empresarial inherente en cada uno de los procesos internos y externos de la misma, donde la Administración de Riesgos entra a formar parte fundamental con la única determinación de identificar, medir, implementar estrategias, monitorear y controlar cada riesgo posible y existente en el entorno de la entidad, de tal forma que sus intereses, patrimonio y activos no presenten afectaciones que marquen un antes y después de cada una de ellas.

Cabe recordar que el riesgo viene mancomunado de la incertidumbre, con esto podemos decir que la administración de riesgos son todas las acciones coordinadas que nos permitan responder y controlar la incertidumbre de un evento potencial (Mejía-Quijano, 2006). Donde se involucran a cada uno de los empleados y departamentos, hoy por hoy se reconoce que los modelos de alta gerencia y gestión empresarial la aplican como una parte fundamental en cada uno de los procesos y desde todos los ángulos posibles, con el fin de que aporten estrategias y decisiones oportunas de cara al riesgo presentado, por ello no podemos decir que el riesgo no esté presente, pero si en gran impacto se evitará y mitigará.

Al adentrarnos al entorno cooperativo donde se ubica nuestra investigación, podemos observar a simple vista que este sector ha crecido en los últimos años en intervención financiera y cooperación con la sociedad, quienes en su momento no tenía acceso a la banca; donde su función es el apoyo de sus asociados en actividades de emprendimiento, pequeños, medianos negocios y desarrollo económico del sector donde se ve involucrada directamente con la sociedad, por ello, la importancia de guardar un correcto plan de riesgos, ya que si se ve afectado de alguna manera este pilar, será perjudicial, no solo para el ente financiero, sino también para el desarrollo económico de la sociedad en general; actualmente para las cooperativas el riesgo toma una participación muy importante ya que está variable es considerada una gestión necesaria para implementar 


\section{CIENCIAMATRIA \\ Revista Interdisciplinaria de Humanidades, Educación, Ciencia y Tecnología \\ Año VII. Vol. VII. N¹2. Enero - Junio. 2021 \\ Hecho el depósito de ley: pp201602FA4721 \\ ISSN-L: 2542-3029; ISSN: 2610-802X \\ Universidad Nacional Experimental Francisco de Miranda (UNEFM). Santa Ana de Coro. Venezuela}

Edgar Fernando Arévalo-Jara; Mariella Johanna Jácome-Ortega;

Cristián Andrés Erazo-Álvarez

un manejo adecuado del plan estratégico, financiero y operacional (Heredia-González, 2015).

Donde la Superintendencia de Economía Popular y Solidaria "SEPS" que inicio su gestión el 05 de junio del 2012, forma parte medular de esta gestión ya que mediante normativas las entidades que bajo este control se encuentren deberán implementar procesos para la administración de riesgos donde evoluciona con el fin de que sea integral, de ahí nace el desarrollar una administración orientada a mitigar los principales riesgos en las cooperativas, así evitando un trastorno financiero y social, desde este punto de partida el sector cooperativo toma un rumbo encaminado a priorizar la solvencia como eje fundamental del crecimiento responsable dentro de la sociedad.

Es por ello que ejercer una administración integral del riesgo se vuelve no solo prioridad sino también el cumplimiento de las normativas del medio de control SEPS que define como tipos de riesgos a los de crédito, liquidez, mercado, operativo y legal, los cuales deberán ser analizados mediante estructuras del organismo interno y miembros del comité, donde se establece como proceso la administración integrada del riesgo donde se define como el alcance de no solo tratar los riesgos sino de comunicar, entender y administrar los riesgos de una forma global (Bueno, et al., 2010).

La Cooperativa Alfonso Jaramillo CAJA nace siendo parte de la Cámara de Comercio y lleva 57 años de contribución financiera al sector productivo y empresarial mediante el apoyo cooperativista de la localidad azuaya, actualmente se sitúa en el segmento 2 dentro del sector cooperativo y con las normativas de la SEPS establece la administración de riesgos integrales; igualmente a sus semejantes, esta investigación se aplica, debido a que actualmente la ejecución y optimización de la administración de Riesgos en la cooperativa CAJA no posee un sistema de medición para generar una estrategia ideal con la que se mitigue el riesgo existente en cada uno de los procesos, evitando así en mayor medida la generación de problemas de un riesgo incontrolable a futuro. 


\section{CIENCIAMATRIA}

Revista Interdisciplinaria de Humanidades, Educación, Ciencia y Tecnología

Año VII. Vol. VII. N¹2. Enero - Junio. 2021

Hecho el depósito de ley: pp201602FA4721

ISSN-L: 2542-3029; ISSN: 2610-802X

Universidad Nacional Experimental Francisco de Miranda (UNEFM). Santa Ana de Coro. Venezuela

Edgar Fernando Arévalo-Jara; Mariella Johanna Jácome-Ortega;

Cristián Andrés Erazo-Álvarez

El riesgo, en toda empresa es un obstáculo para seguir desarrollándose y ampliándose de alguna manera, por ello se debería buscar desde sus cimientos las deficiencias que generan estos riesgos, a fin de buscar soluciones para atenuar dichos riesgos y con ello en un futuro inmediato llegar a alcanzar los objetivos para los que fue creada.

Por eso se propone determinar estrategias para reducir los riesgos presentados dentro de la Cooperativa, con la implementación de la Distancia Relativa de Hamming como un proceso de metodología para atrapar la incertidumbre (riesgo), obteniendo una participación combinada con los expertos, sus definiciones, conocimientos y experiencia personal en el sector cooperativo por medio de la encuesta, de esta manera se pretende obtener la mejor estrategia que se adecue a la propuesta ideal y de los intereses dentro de la cooperativa.

\section{Referencial Teórico}

\section{La importancia de identificar el riesgo desde una visión global}

Desde que apareció el hombre, la incertidumbre inicio con él y por ende su asociación con el riesgo por muchas situaciones vividas día a día; la incertidumbre del que comerá, que vestirá, como sobrevivirá, que pasará con él para un determinado problema, tomó un papel importante para su evolución. No solo en el pasado se vivía con incertidumbre y riesgo, hoy por hoy también existen estas dos variables que no solo afecta nuestro diario vivir, sino también a las grandes empresas, los cuales buscan dar soluciones de manera inmediata y resultados positivos en su totalidad. La incertidumbre se encuentra presente a corto plazo y se activa por la incapacidad de identificar eventos que afloren con sus consecuencias; es decir la incertidumbre viene asociado el riesgo (Mejía-Quijano, 2004). Podemos definir que el riesgo se remonta a tiempos inmemoriales de la misma humanidad, es decir, desde lo más común se define como la probabilidad de perder algo o de tener un resultado no deseado, negativo ni peligroso (Echemendía-Tocabens, 2011). El Manual de Riesgo de la Cooperativa Alfonso Jaramillo León, CAJA define al riesgo 


\section{CIENCIAMATRIA \\ Revista Interdisciplinaria de Humanidades, Educación, Ciencia y Tecnología \\ Año VII. Vol. VII. N¹2. Enero - Junio. 2021 \\ Hecho el depósito de ley: pp201602FA4721 \\ ISSN-L: 2542-3029; ISSN: 2610-802X \\ Universidad Nacional Experimental Francisco de Miranda (UNEFM). Santa Ana de Coro. Venezuela}

Edgar Fernando Arévalo-Jara; Mariella Johanna Jácome-Ortega;

Cristián Andrés Erazo-Álvarez

como la probabilidad de que se produzca el evento que genere pérdida con un determinado nivel de impacto en la entidad; pero hay quienes consideran que el riesgo también se puede interpretar de una manera positiva, entonces puede servir para medir la probabilidad de desarrollar con éxito las estrategias definidas por la organización, para así alcanzar los objetivos, sean globales, funcionales o por proceso (Rojas, 2002). De cualquier ángulo que pueda ser visto el riesgo, se lo debe considerar como una oportunidad, que nos permite una detección con un control proactivo, y en eso se basará al presente trabajo, en buscar los riesgos de la institución Cooperativa Alfonso Jaramillo León CAJA, y buscar soluciones por medio de estrategias para así mitigar los riesgos encontrados.

Existen varios trabajos realizados sobre los riesgos en general, actualmente se han estudiado en un contexto empresarial y se los puede listar según (Bolaño-Rodríguez, et al., 2014). De la siguiente manera:

1. Riesgos asociados a eventos laborales

2. Riesgos asociados a eventos ambientales

3. Riesgos relacionados con la calidad

4. Riesgos asociados a eventos financieros (de mercado, de créditos, de liquidez)

5. Riesgos asociados con operaciones

6. Riesgos asociados a eventos estratégicos

7. Riesgos asociados a la logística y cadenas de producción

8. Riesgos asociados a la tecnología de la información.

De este modo se puede evidenciar que existen varios riesgos del lado empresarial, pero como objeto de este estudio se definirá únicamente los riesgos financieros, donde se basa nuestra investigación, con referencia a lo ya citado podemos añadir qué a más de liquidez, crédito, mercado, existe el operativo y legal, aspectos que la Superintendencia de Economía Popular y Solidaria determina importante para una administración integral de riesgos. El libro medición y control de riesgos financieros. 


\section{CIENCIAMATRIA \\ Revista Interdisciplinaria de Humanidades, Educación, Ciencia y Tecnología \\ Año VII. Vol. VII. N¹2. Enero - Junio. 2021 \\ Hecho el depósito de ley: pp201602FA4721 \\ ISSN-L: 2542-3029; ISSN: 2610-802X \\ Universidad Nacional Experimental Francisco de Miranda (UNEFM). Santa Ana de Coro. Venezuela}

Edgar Fernando Arévalo-Jara; Mariella Johanna Jácome-Ortega;

Cristián Andrés Erazo-Álvarez

Por otro lado, (De Lara Haro, 2005) define como riesgo de liquidez a la fugas de recursos que pueda sufrir una empresa de cualquier tipo al contraer una mayor cantidad de recursos necesarios en su momento, convirtiéndose dicha adquisición en algo difícil de cubrir, riesgo de crédito se puede definir como desventaja para la empresa por el incumplimiento de la contraparte en una situación determinada, que se media por un compromiso de pago, riesgo de mercado es la perdida que puede sufrir una entidad, empresa o institución.

Debido a la modificación en los precios que se registran en el mercado o en movimiento de los llamados factores de riesgo (tasas de interés, tipos de cambio, etc.), riesgo legal se refiere a todas las pérdidas que puede sufrir una empresa o institución por la falta de cumplimento de la contraparte, exigible por la vía jurídica con la finalidad de que se cumpla las obligaciones contraídas. También se puede definir como errores contractuales, y riesgo operativo es una definición muy amplia que se correlaciona con errores en sistemas, procesos, modelos o en el personal que desempeñan dichas acciones, también se lo puede asociar con pérdidas por estafas o por la falta de procesos de capacitación (De Lara Haro, 2005, p. 16-17).

\section{La implementación de una administración de riesgos empresariales}

Para minimizar los riesgos es preciso guardar un orden, y esto se puede lograr por medio de una administración, de ahí nace la administración de riesgos que se define como la forma de alertar de una manera inmediata con el fin de resguardar los intereses de la institución, que le admita identificar los riesgos, aportando metodologías que puedan cambiar constantemente al responder cada riesgo y desarrollar acciones adaptables que asegure los recursos de la institución en mitigar cada riesgo (Mejía-Quijano, 2004).

Para tener una idea general, podemos decir que la administración riesgos es uno de los medios más importantes dentro de las empresas, características del tiempo y los requerimientos de trabajo que distinguen a la humanidad, para ello debe estar 


\section{CIENCIAMATRIA \\ Revista Interdisciplinaria de Humanidades, Educación, Ciencia y Tecnología \\ Año VII. Vol. VII. N¹2. Enero - Junio. 2021 \\ Hecho el depósito de ley: pp201602FA4721 \\ ISSN-L: 2542-3029; ISSN: 2610-802X \\ Universidad Nacional Experimental Francisco de Miranda (UNEFM). Santa Ana de Coro. Venezuela}

Edgar Fernando Arévalo-Jara; Mariella Johanna Jácome-Ortega;

Cristián Andrés Erazo-Álvarez

incorporada dentro de la organización a través de procesos que impliquen a los empleados con el fin de su aplicación sea integral dentro de la entidad. Una óptima Administración de Riesgos se centraliza en la visión y corrección de los riesgos para maximizar la posibilidad del éxito y minimizar las posibilidades del fracaso como la fluctuación de lograr la visión y propósitos globales de la institución (Cuello-Lascano, et al., 2008). Ahora bien, si el riesgo es inherente a toda empresa o institución, es más para una entidad financiera.

La administración de riesgo aparte de ser una disciplina enfocada a decisiones y acciones proactivas, debe obtener la participación de todo el personal y en especial del equipo de trabajo que maneja está función de medir el riesgo continuamente de una manera organizada para una toma de decisiones en pro a la rentabilidad y estabilidad de la entidad, ahora si bien la medición es continua hay quienes solo la consideran en la planeación preliminar.

Muchas de las entidades en nuestro entorno, consideran a la administración de riesgo como algo superficial, sin necesidad de aplicarla o considerarla, por ello es indispensable demostrar la importancia de tener una administración orientada a los posibles riesgos que presentan en cada ámbito ya que solo tratando de evitarlos no producirá ningún cambio al bienestar de dicha entidad, hay que evaluar cada uno de ellos; Como inicio se deberá evaluar los riesgos para poder mitigarlos. Estupiñán-Gaitán (2015) lo considera la evaluación de riesgos "es la identificación y análisis de los riesgos que se relacionan con el logro de los objetivos; la administración debe cuantificar su magnitud, proyectar su probabilidad y sus posibles consecuencias" (p. 384). Entonces una evaluación correcta en las entidades en general, sea cual sea su accionar, se verán beneficiadas en todos los ámbitos ya sean estos financieros y administrativos.

Contar con la administración de riesgos en las entidades, es importante porque permite crear estrategias para identificar problemas en las que se pueda ver afectada en sus actividades normales, entender cómo pueden afectar las amenazas a la entidad o 
CIENCIAMATRIA

Revista Interdisciplinaria de Humanidades, Educación, Ciencia y Tecnología

Año VII. Vol. VII. N¹2. Enero - Junio. 2021

Hecho el depósito de ley: pp201602FA4721

ISSN-L: 2542-3029; ISSN: 2610-802X

Universidad Nacional Experimental Francisco de Miranda (UNEFM). Santa Ana de Coro. Venezuela

Edgar Fernando Arévalo-Jara; Mariella Johanna Jácome-Ortega;

Cristián Andrés Erazo-Álvarez

institución para llegar a la reacción de acciones o estrategias para mejorar la situación o problemática presente, para ello Estándar Australiano presenta una vista general de la manera correcta de plantear una administración de riesgos, a fin de tenerla como base para el desarrollo ya de un estudio bien elaborado y tomarlo como base para entablar los próximos problemas orientados al riesgo, en la siguiente figura 1:

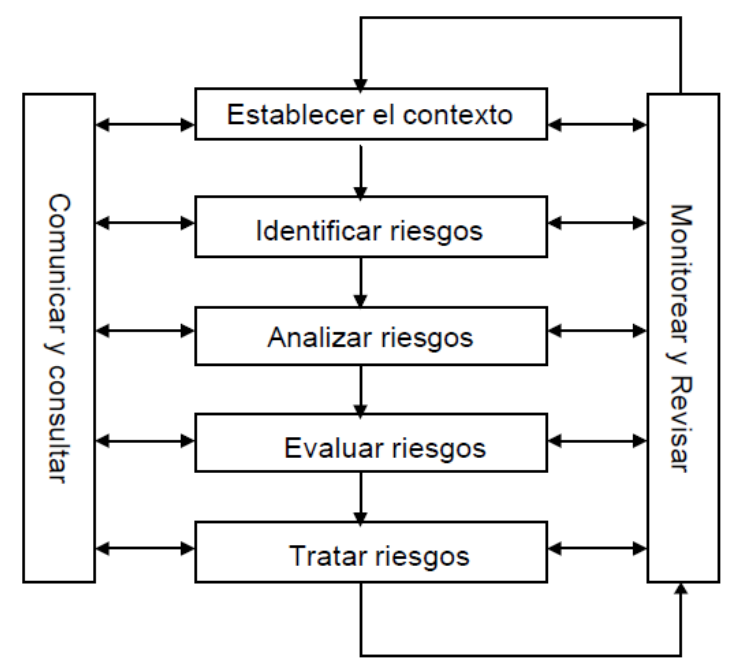

Figura 1. Vista General de la Administración de Riesgos.

Fuente: Estándar Australiano de Administración del Riesgo AS/NZS 4360 (1999).

Como primer paso se puede observar establecer el contexto que es la correlación que existe entre la entidad y su entorno en la cual opera, aquí se armonizan los objetivos, intereses internos, externos, estrategias, misión, visión, procesos e incluso niveles más mínimos con el fin que no se pase por alto el riesgo más significativo.

El segundo paso es la identificación de riesgos, esto comprenderá a toda la entidad y sus procesos que estén expuestas a riesgos, de forma conjunta con el personal y su experiencia en cada proceso asignado serán claves para identificar el riesgo dentro de ese proceso, Estándar Australiano propone 2 preguntas claves, ¿qué puede suceder?, 


\section{CIENCIAMATRIA \\ Revista Interdisciplinaria de Humanidades, Educación, Ciencia y Tecnología \\ Año VII. Vol. VII. N¹2. Enero - Junio. 2021 \\ Hecho el depósito de ley: pp201602FA4721 \\ ISSN-L: 2542-3029; ISSN: 2610-802X \\ Universidad Nacional Experimental Francisco de Miranda (UNEFM). Santa Ana de Coro. Venezuela}

Edgar Fernando Arévalo-Jara; Mariella Johanna Jácome-Ortega;

Cristián Andrés Erazo-Álvarez

¿cómo y por qué pueden suceder?, estos dos enfoques abarcan un mayor abanico de posibles riesgos por más mínimo que sea.

El tercer paso es el análisis del riesgo, siendo fundamental, ya que aquí se concentrará desde los riesgos menores hasta el mayor, con el fin de determinar el impacto que presenta en cada proceso, llegando a generar el tratamiento correcto para cada uno de los riesgos, siguiendo con el mismo autor nos indica que se analiza el riesgo mezclando apreciaciones de consecuencias y probabilidades con argumentos de las métricas de control vigentes (Estándar Australiano de Administración del Riesgo AS/NZS 4360:1999). Esto generara un nivel de riesgo, para tratarlo cualitativamente y cuantitativamente, obteniendo así datos estadísticos del impacto de cada riesgo.

El cuarto paso sería la evaluación del riesgo que consiste en entablar semejanzas y diferencias en el proceso de estudio, apoyándose en criterios recopilados con antelación, por ello como resultado de este paso sería la búsqueda de variables para encontrar una solución a la misma, esas variables deben tener un amplio contexto, pero, sin dejar al lado una correlación entre la tolerancia del riesgo y el beneficio que esto implica.

El último paso es el tratamiento de los riesgos, esto implica una identificación de todas las opciones para diagnosticar el riesgo, evaluar estas opciones, planificar estrategias e implementarlas ya sean individualmente o combinadas, esto también debe estar a la mano de un gasto, es decir si el riesgo es mitigado con un gasto sensatamente bajo las estrategias deberían aplicarse y si el gasto es mayor debería analizarse si justifica aplicarlas para ese riesgo, aquí se aplica costo-beneficio.

Como se puede evidenciar en el cuadro el monitoreo y la revisión, así como la comunicación y consulta se aplica en todos los pasos, con el fin de que retroalimente el impacto de cada proceso y estrategia que se debería implementar durante todo este proceso.

Los riesgos y la confianza de las métricas de control necesitan ser inspeccionadas con el fin de resguardar cambios que puedan alterar las prioridades de los riesgos. Algunos 


\section{CIENCIAMATRIA \\ Revista Interdisciplinaria de Humanidades, Educación, Ciencia y Tecnología \\ Año VII. Vol. VII. N¹2. Enero - Junio. 2021 \\ Hecho el depósito de ley: pp201602FA4721 \\ ISSN-L: 2542-3029; ISSN: 2610-802X \\ Universidad Nacional Experimental Francisco de Miranda (UNEFM). Santa Ana de Coro. Venezuela}

Edgar Fernando Arévalo-Jara; Mariella Johanna Jácome-Ortega;

Cristián Andrés Erazo-Álvarez

riesgos son constantes y deben revisarse permanentemente para asegurar de que el objetivo inicial se mantenga el esquema de cómo debería ser la correcta administración de riesgos, anteriormente citado, propone la documentación de cada fase del proceso de administración de riesgos, detallado en los siguientes puntos a) aclarar que el proceso es llevado acertadamente; b) administrar relación de una perspectiva metodológica de identificación y análisis de riesgo; c) administrar una observación de los riesgos y aplicar las buenas prácticas de la institución; d) generar decisiones acertadas de un esquema de administración de riesgos validar e implementar acciones; e) administrar componentes y herramientas de responsabilidad; f) Fácil acceso a una supervisión; g) proporcionar auditorias; y h) guardar correlación entre informar y compartir información relevante (Bueno, et al., 2010).

\section{Planteamiento de alternativas para mitigar el riesgo}

Conocedores de que la mejor manera de mitigar el riesgo en cualquier ámbito es establecer un proceso profundo de identificación en cada área y un posterior tratamiento aplicable a cualquier entidad que lo amerite, es fundamental definir al sector cooperativo, el Artículo 21.- Ley Orgánica de la Economía Popular y Solidaria y del Sector Financiero Popular y Solidario lo conceptualiza como el conjunto de cooperativas anexadas de una sociedad de personas que de forma voluntaria se unieron para satisfacción de varias necesidades como las económicas, sociales y culturales que presentaban en común, mediante una institución de su propiedad y de una gestión democrática, con representación jurídica de derecho privado e intereses sociales.

El sector cooperativo es el más relevante dentro de la Economía Popular y Solidaria, comprendido por asociaciones, cajas y bancos comunales, formado y gobernado por la voluntad de sus socios, las cooperativas, en su actividad y relaciones, se sujetarán a los principios universales y valores del cooperativismo y a las prácticas de buen gobierno corporativo, existen varios tipos de cooperativas de acuerdo con el artículo 23 de la 


\section{CIENCIAMATRIA \\ Revista Interdisciplinaria de Humanidades, Educación, Ciencia y Tecnología \\ Año VII. Vol. VII. N¹2. Enero - Junio. 2021 \\ Hecho el depósito de ley: pp201602FA4721 \\ ISSN-L: 2542-3029; ISSN: 2610-802X \\ Universidad Nacional Experimental Francisco de Miranda (UNEFM). Santa Ana de Coro. Venezuela}

Edgar Fernando Arévalo-Jara; Mariella Johanna Jácome-Ortega;

Cristián Andrés Erazo-Álvarez

LOEPS las cooperativas, según la actividad principal pertenecerán a los siguientes grupos: ahorro y crédito, producción, consumo, vivienda y servicios las cuales cuentan con una Asamblea General de socios o representantes que es el máximo órgano de gobierno, quienes forman parte de este grupo colegiado tienen derecho a la voz y a un solo voto, sin considerar el monto de sus aportaciones, un Consejo de Administración es la parte directiva y de creación reglas de la cooperativa, un Consejo de Vigilancia es un ente interno de control sobre las acciones económicas que sin influencia de la administración responde a la Asamblea General y la Gerencia que es el representante legal, judicial extra judicial de la cooperativa, responsable de su administración y gestión, de acuerdo con el artículo 32 de la LOEPS (Mejía-Caguasango, 2017). Con esta identificación se logra una mayor apreciación del sector a donde se direcciona la investigación.

Para la argumentación del trabajo en sí, se establecerá como punto de partida la implementación de la herramienta de Hamming para determinar la variable ideal y cuál de las estrategias se dista en menor porcentaje a lo ideal dentro de la Cooperativa Alfonso Jaramillo León CAJA, ya que por ser una institución financiera está expuesta a varios riesgos que afronta este mismo sector financiero, es por ello que se otorgara por medio de esta investigación y soluciones aplicativas a corto, mediano y largo plazo.

La distancia de Hamming es una es una herramienta que se fundamenta en los conjuntos de números difusos o borrosos que constituye la integración de elementos o conjunto de elementos a una clasificación o patrón, incidencia que se expresa con mayores grados de acuerdo con la opinión de expertos (Carrión-Agila, et al., 2019). En otras palabras, consiste en ponderar ciertas competencias de acuerdo con la importancia donde 1 es lo más cercano y 0 el que más se aleja del perfil ideal, de tal manera que todas las posibilidades entran a la medición de forma equivalente, además, se ha demostrado que se puede realizar una búsqueda exacta del vecino más cercano en el espacio de Hamming de forma más rápida que la búsqueda lineal. 
CIENCIAMATRIA

Revista Interdisciplinaria de Humanidades, Educación, Ciencia y Tecnología

Año VII. Vol. VII. N¹2. Enero - Junio. 2021

Hecho el depósito de ley: pp201602FA4721

ISSN-L: 2542-3029; ISSN: 2610-802X

Universidad Nacional Experimental Francisco de Miranda (UNEFM). Santa Ana de Coro. Venezuela

Edgar Fernando Arévalo-Jara; Mariella Johanna Jácome-Ortega;

Cristián Andrés Erazo-Álvarez

De esta manera la fórmula de la distancia relativa de Hamming que se implementará es lo más semejante a lo ideal.

\section{Ecuación 1: Aproximación al proceso óptimo (ठ)}

$$
\boldsymbol{\delta}\left(\mathbf{D}_{n}, \boldsymbol{P}_{j}\right)=1 / n \sum_{i, j=1}^{n}\left|\mu_{i}-\mu_{j}\right|=\mathbf{1} / \boldsymbol{n}\left(\left|\mu_{1}-\mu_{j}\right|+\left|\mu_{2}-\mu_{j}\right|+\cdots+\left|\mu_{n}-\mu_{j}\right|\right)
$$

Donde $D_{n}$ : Subconjunto borroso de competencias óptimas; $\mathrm{P}_{\mathrm{j}}$ subconjunto borroso de competencias reales; n: número de competencias seleccionadas; ui: valoración de competencia óptima; uj: valoración de competencia real evaluada (Soler, et al., 2016).

Al utilizar esta herramienta como instrumento, nos servirá para la obtención de datos y estrategias para determinar cuál es la ponderación de los expertos en cada uno de los riesgos dentro de la Cooperativa, se utilizará además en la investigación la recolección de información en base a fuentes oficiales como lo es la SEPS y otras entidades relacionadas con las cooperativas y otras fuentes recolectadas con opiniones de colaboradores de la institución, además la técnica utilizada para la recolección de la información será encuestas.

Las encuestas obtienen información sistemática de los encuestados a través de preguntas, ya sea personales, telefónicas o por correo (Thompson, 2006). Teniendo en cuenta esta definición nos basaremos en obtener toda la información posible de los antecedentes de la empresa, personal directivo, gerentes y/o jefes de área; para determinar la variable ideal como referencia de la mitigación de los riesgos, es decir por medio de la encuesta pretendemos buscar la información de una manera jerarquizada, en donde se pregunte a las personas encuestadas sobre los datos que desean obtener, y para luego con estos datos individuales nos servirán para mejorar la problemática visible en la entidad. 


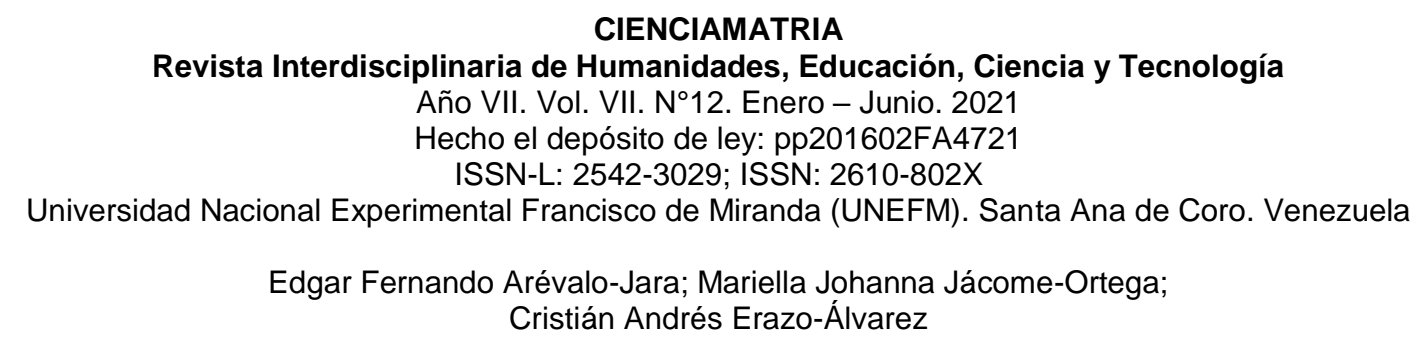

Para tener una idea más clara de la importancia de la encuesta en nuestro estudio podemos acotar que existen varios tipos de preguntas que podemos considerar antes de fabricar un cuestionario, por ejemplo, las encuestas o cuestionarios pueden ser según la naturaleza del contenido, atendiendo a su contenido sobre los temas concretos o hechos objetivos, opiniones, información, aspiraciones, etc. $Y$ también se encuentran los cuestionarios según su función estas son para una selección de encuestados con el objeto de generar un control y determinar la veracidad de la información encuestada (Anguita, Labrador, \& Campos, 2003). De ahí la importancia de las encuestas en el presente trabajo, puesto que por medio de estas podemos intervenir más a fondo en la institución con la que vamos a trabajar y así visualizar de manera clara los problemas de riesgo que tiene y a su vez mejorar esta situación.

A más de aplicar estas herramientas y tener presente los conceptos más importantes, será necesario tener claro el organigrama de la gestión integral de riesgos que propone el ente de control SEPS para todo el sector de la Economía Popular y Solidaria y la cual está aplicando la Cooperativa Alfonso Jaramillo León CAJA.

Según el Manual de Riesgos de la Cooperativa Alfonso Jaramillo León CAJA la administración de riesgos es la metodología el cual las instituciones podrán identificar, medir, priorizar, controlar, mitigar, monitorear y comunicar todos los riesgos posibles dentro de la mismas, siempre que estén de la mano de una estrategia o acciones que se encuentren debidamente planificadas, con el fin de llegar a los objetivos planteados (Cooperativa CAJA, 2018). Con ello se determina como organigrama que aplica la cooperativa figura 2 : 


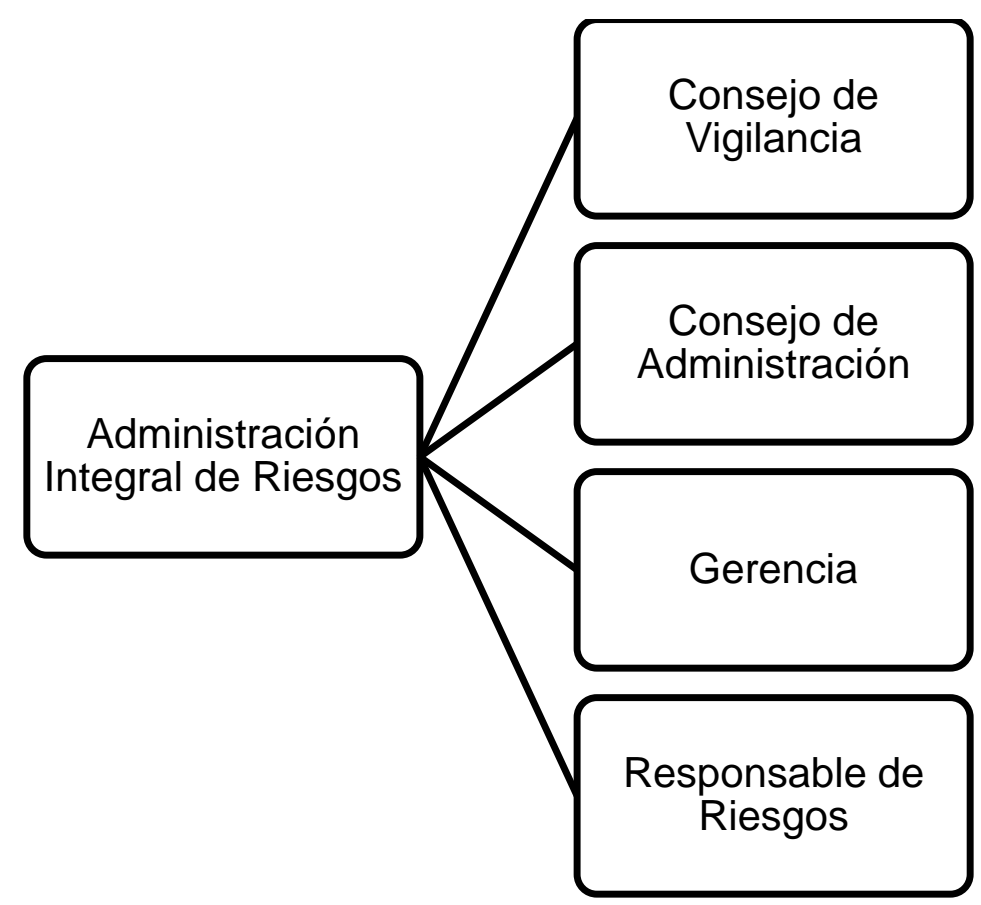

Figura 2. Organigrama de la estructura de la gestión integral de riesgos. Manual de Administración de Riesgos Código MA-AYC-01.

Fuente: Cooperativa CAJA (2018).

De conformidad la Resolución Nro.128-2015-F el Comité de Administración para una adecuada administración de riesgos verificará:

1. Las implementaciones de políticas, derivado de sus procesos, metodologías y formando estrategias para una administración integral de riesgos

2. Ratios financieras de exposición de los riesgos presentes

3. Detalle de las calificaciones de los riesgos activos

4. El estudio de riesgos posibles sobre nuevos lanzamientos de productos o servicios

5. El plan estratégico y matriz de los riesgos institucionales

6. Informes de todas estas apreciaciones con sus respectivas correcciones en casa de incumplimiento.

7. Implementación del manual de administración integral de riesgos

8. Una ruta de trabajo de contingencia continua del negocio 


\section{CIENCIAMATRIA}

Revista Interdisciplinaria de Humanidades, Educación, Ciencia y Tecnología

Año VII. Vol. VII. N¹2. Enero - Junio. 2021

Hecho el depósito de ley: pp201602FA4721

ISSN-L: 2542-3029; ISSN: 2610-802X

Universidad Nacional Experimental Francisco de Miranda (UNEFM). Santa Ana de Coro. Venezuela

Edgar Fernando Arévalo-Jara; Mariella Johanna Jácome-Ortega;

Cristián Andrés Erazo-Álvarez

9. Otros aspectos que consideren el consejo administrativo o la superintendencia.

Siendo un organismo colegiado y compuesto por varios integrantes del organigrama ya mencionado, son los que realizan la vigilancia de los riesgos financieros y los expertos que aportarían a la ejecución de este sistema de medición. Por ello en este trabajo se tendrá presentes aportaciones de este organismo, por medio de la investigación realizada se compacten, a fin de buscar la mitigación de los riegos, que es el objetivo del presente estudio.

Estas son algunas de las razones por las que se ha tomado como una técnica de investigación la encuesta, ya que nos servirá para aclarar más nuestra temática y encontrar las verdaderas ponderaciones que los expertos asumen de los riesgos de la empresa a intervenir, y de esta manera mitigar los riesgos presentes con estrategias que mejor se adecue a lo ideal para mantener una adecuada posición de solidez, liquidez y solvencia.

Buscar la solución al problema principal que es la mitigación de los riesgos empresariales es un tema muy amplio, por ello en la presente investigación lo que se busca es que, por medio de herramientas y recopilación de información de diversos autores y aplicación de conocimientos, delimitar las estrategias ideales para la mitigación de los riesgos en las cooperativas específicamente en la Cooperativa de Ahorro y Crédito, Cooperativa CAJA.

\section{MÉTODO}

Esta investigación metodológicamente es de tipo descriptivo-explicativo, ya que se aplicó la distancia relativa de Haming para clasificar las estrategias ideales con el que se pretende la mitigación de cada uno de los riesgos en la Cooperativa CAJA, el objetivo es mejorar el proceso para un mayor análisis con mejores y visibles resultados, para ello se usó el enfoque mixto de datos cualitativos, visibles en las estrategias planteadas y lo teórico de la información obtenida al inicio de la investigación para el estudio, enlazado con la parte cuantitativa que fue el resultado estadístico de la observación de los datos 


\section{CIENCIAMATRIA \\ Revista Interdisciplinaria de Humanidades, Educación, Ciencia y Tecnología \\ Año VII. Vol. VII. N¹2. Enero - Junio. 2021 \\ Hecho el depósito de ley: pp201602FA4721 \\ ISSN-L: 2542-3029; ISSN: 2610-802X \\ Universidad Nacional Experimental Francisco de Miranda (UNEFM). Santa Ana de Coro. Venezuela}

Edgar Fernando Arévalo-Jara; Mariella Johanna Jácome-Ortega;

Cristián Andrés Erazo-Álvarez

por medio de una encuesta aplicada en google formularios, de esta combinación se representó la información encontrada y se llegó al análisis de cada respuesta.

Para realizar el análisis se destinó un alcance al caracterizar la situación concreta de los riesgos que presenta la cooperativa e indicando sus rasgos más peculiares o diferenciadores, en busca del porqué de los hechos mediante el establecimiento de relaciones causa-efecto, para así platear las estrategias y mitigar los riesgos.

Las técnicas utilizadas en la recopilación de datos fueron: las encuestas y la revisión documental, el universo de estudio estaba conformado por el personal administrativo involucrado en el área de riesgos, para lo cual se aplicó el método de muestreo de conveniencia, ya que se seleccionó por métodos no aleatorios y de modo subjetivo la muestra con características similares a las de la población objetiva, y al elegir a todo el personal involucrado en riesgos se puede cuantificar la representatividad de la muestra, al ser una muestra total del área en cuestión (Casal \& Mateu, 2003).

\section{RESULTADOS}

Esta investigación toma como base las encuestas realizadas al área involucrada directamente con el análisis de los riesgos, para ello se inició con las siguientes dimensiones que fueron analizadas:

La primera dimensión fue la de toma de decisiones dentro de la Cooperativa Caja donde el $46.7 \%$ posee una toma de decisión alta el $13.3 \%$ una toma de decisión media y el $40 \%$ una toma de decisión baja.

Posterior se analizaron las dimensiones para cada riesgo y su importancia de mitigar cada uno de ellos, comenzando por el riesgo de crédito, en donde las situaciones que generan un mayor riesgo de crédito con el $86.7 \%$ considera que el incumplimiento a las políticas, el $6.7 \%$ la falta de información sobre las situaciones vulnerables y el $6.7 \%$ que los procesos no son adecuados para la aprobación de los diferentes montos y la 


\section{CIENCIAMATRIA \\ Revista Interdisciplinaria de Humanidades, Educación, Ciencia y Tecnología \\ Año VII. Vol. VII. N¹2. Enero - Junio. 2021 \\ Hecho el depósito de ley: pp201602FA4721 ISSN-L: 2542-3029; ISSN: 2610-802X \\ Universidad Nacional Experimental Francisco de Miranda (UNEFM). Santa Ana de Coro. Venezuela}

Edgar Fernando Arévalo-Jara; Mariella Johanna Jácome-Ortega;

Cristián Andrés Erazo-Álvarez

importancia de mitigación de este riesgo es del 53.3\% lo más importante y el $46.7 \%$ importante.

La siguiente dimensión es el riesgo de liquidez donde las situaciones que generan un mayor riesgo con el $46.7 \%$ es la falta de fondos disponibles, con un $26.7 \%$ es las tasas de captaciones altas, el $20 \%$ considera que es la fuga de depósitos a corto plazo y el $6.7 \%$ aprecia que es la falta de financiación externa, dentro de la importancia de mitigar este riesgo el $33.3 \%$ considera lo más importante e importante, un $20 \%$ considera bastante importante mientras que solo el 13,3\% lo considera muy importante.

Para el riesgo de mercado las situaciones que generan un mayor riesgo con el $46.7 \%$ es las variaciones económicas del país con respecto a la moneda, el $26.7 \%$ indica que son los cambios de las tasas activas y pasiva, el $20 \%$ por imagen institucional y el $6.7 \%$ el devaluó de los activos y su importancia de mitigación de este riesgo el 33.3\% lo deduce como lo más importante, el $26.7 \%$ como más importante que menos importante, el 20\% tan importante como no importante, el $13.3 \%$ como importante y el $6.7 \%$ muy importante. En el riesgo operativo se considera que las situaciones que generan mayor riesgo con un $86.7 \%$ son los procesos no establecidos y definidos y el $13.3 \%$ personal inadecuado en áreas estratégicas, para la mitigación de este riesgo el 33.3\% considera que es lo más importante mientras que un $20 \%$ lo considera importante y el $13.3 \%$ lo considera como muy importante, más importante que menos importante y tan importante como menos importante y el $6.7 \%$ menos importante que importante.

$Y$ para finalizar las situaciones que mayor riesgo legal generan son con el $40 \%$ el incumplimiento legal y normativo, el $33.3 \%$ documentación contractual errónea y el $26.7 \%$ procesos vulnerables de las operaciones del giro financiero, entre la prioridad de mitigar este riesgo podemos decir que el $40 \%$ lo considera lo más importante, el $33.3 \%$ bastante importante, el $13,3 \%$ muy importante y el $6.7 \%$ más importante que menos importante y tan importante como menos importante. 


\section{CIENCIAMATRIA}

Revista Interdisciplinaria de Humanidades, Educación, Ciencia y Tecnología

Año VII. Vol. VII. N¹2. Enero - Junio. 2021

Hecho el depósito de ley: pp201602FA4721

ISSN-L: 2542-3029; ISSN: 2610-802X

Universidad Nacional Experimental Francisco de Miranda (UNEFM). Santa Ana de Coro. Venezuela

Edgar Fernando Arévalo-Jara; Mariella Johanna Jácome-Ortega;

Cristián Andrés Erazo-Álvarez

\section{PROPUESTA}

A continuación, se presenta una estructura donde se plantea las etapas de la administración de riesgos, para establecer una guía de procesos con lo que pretende mitigar cada riesgo.

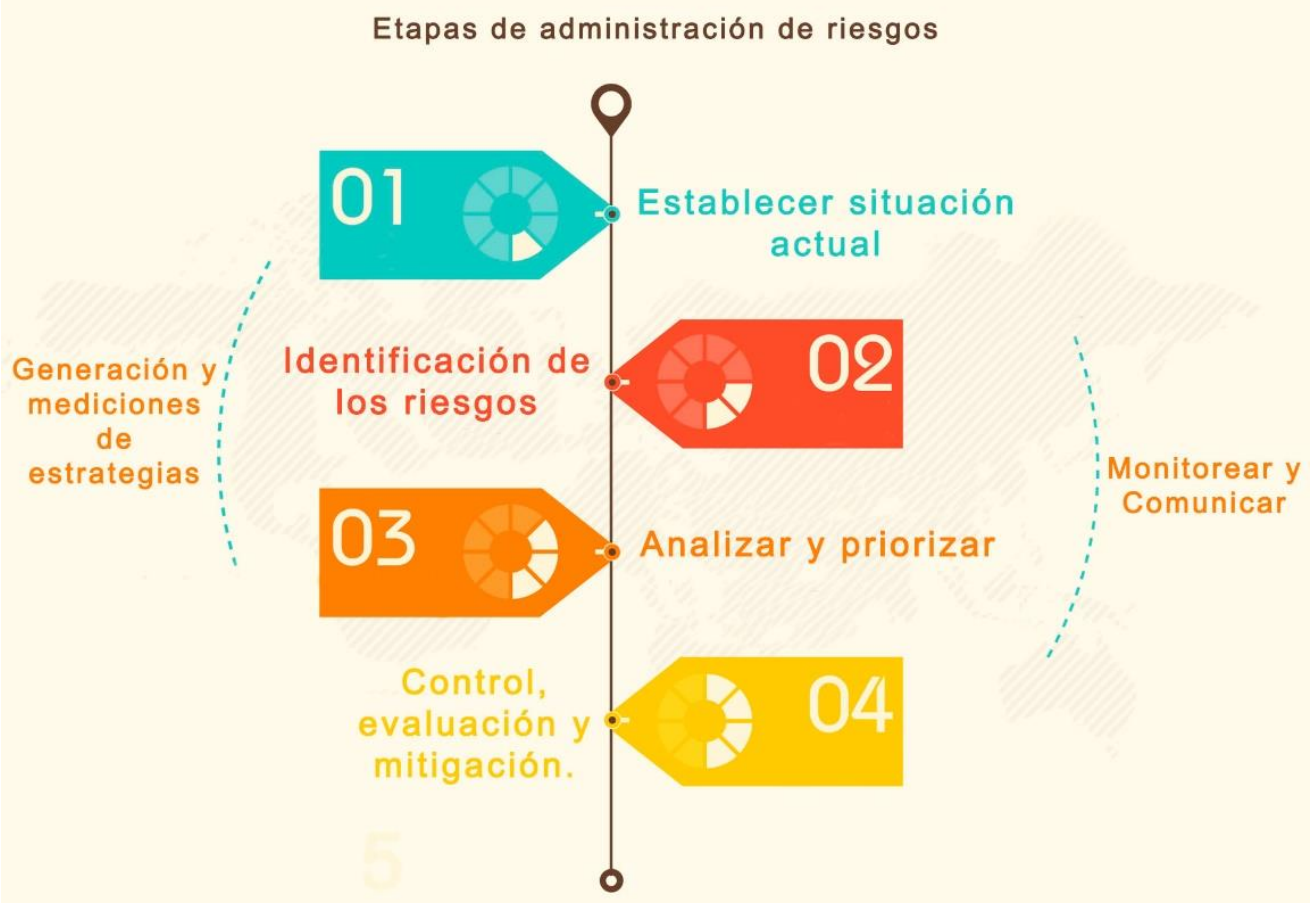

Figura 3. Etapas de administración de riesgos.

\section{Establecer situación actual}

La Cooperativa CAJA es una entidad financiera que se fundó desde hace 57años como parte de la cámara de comercio de Cuenca con el propósito de generar un desarrollo económico de la provincia del Azuay, actualmente se encuentra regulada por la Superintendencia de Economía Popular y Solidaria situada en el segmento 2 de acuerdo con sus activos, a continuación, se detalla el ranking de las cooperativas dentro de este segmento. 
CIENCIAMATRIA

Revista Interdisciplinaria de Humanidades, Educación, Ciencia y Tecnología

Año VII. Vol. VII. N¹2. Enero - Junio. 2021

Hecho el depósito de ley: pp201602FA4721 ISSN-L: 2542-3029; ISSN: 2610-802X

Universidad Nacional Experimental Francisco de Miranda (UNEFM). Santa Ana de Coro. Venezuela

Edgar Fernando Arévalo-Jara; Mariella Johanna Jácome-Ortega;

Cristián Andrés Erazo-Álvarez

\section{Tabla 1.}

Ranking cooperativas del sector financiero popular y solidario según sus activos.

\section{Segmento 2 \\ Periodo del 1 Enero del 2020 al 31 de Octubre del 2020 (Dólares)}

\begin{tabular}{llr}
\multicolumn{1}{c}{ Entidad } & Dólares & Porcentaje \\
Padre Julián Lorente Ltda. & 85.914 .906 & $4,46 \%$ \\
Chone Ltda. & 78.671 .382 & $4,08 \%$ \\
Alfonso Jaramillo León CC. & 77.737 .200 & $4,04 \%$ \\
De La Pequeña Empresa Cacpe Loja Ltda. & 71.792 .729 & $3,73 \%$ \\
Luz Del Valle & 65.642 .482 & $3,41 \%$ \\
Guaranda Ltda. & 65.039 .886 & $3,38 \%$ \\
Calceta Ltda. & 62.346 .075 & $3,24 \%$ \\
9 De Octubre Ltda. & 60.638 .122 & $3,15 \%$ \\
Indígena Sac Ltda. & 58.894 .617 & $3,06 \%$ \\
Virgen Del Cisne & 57.438 .273 & $2,98 \%$ \\
Coopac Austro Ltda. & 53.868 .499 & $2,80 \%$ \\
San Francisco De Asis Ltda. & 48.232 .471 & $2,50 \%$ \\
Construcción Comercio Y Producción Ltda. & 47.781 .116 & $2,48 \%$
\end{tabular}

Fuente: Boletines financieros SEPS

Entre su visión se encuentra en convertirse en la cooperativa más destacada del Austro y su misión en ofertar servicios y productos financieros de vanguardia con el propósito de crear un crecimiento del sector basado en los principios cooperativistas, generando ideas y proyectos para un crecimiento microempresario y fomentando los emprendimientos. 


\section{CIENCIAMATRIA}

Revista Interdisciplinaria de Humanidades, Educación, Ciencia y Tecnología

Año VII. Vol. VII. N¹2. Enero - Junio. 2021

Hecho el depósito de ley: pp201602FA4721

ISSN-L: 2542-3029; ISSN: 2610-802X

Universidad Nacional Experimental Francisco de Miranda (UNEFM). Santa Ana de Coro. Venezuela

Edgar Fernando Arévalo-Jara; Mariella Johanna Jácome-Ortega;

Cristián Andrés Erazo-Álvarez

\section{Identificación de Riesgo}

La Cooperativa en base de las normativas emitidas por el ente regulador de las cooperativas, propone la implementación de procesos para una administración de riesgos de acuerdo con las operaciones y tamaño de la misma, volviéndose parte de los planes estratégicos y decisiones que se implementan.

Para ello es indispensable presentar responsables y comités que evalúen cada uno de los riesgos presentados. Entre ellos se encuentran órganos internos como el consejo de administración, consejo de vigilancia, comité de administración de riesgos integrales, unidad de riesgos y administradores de riesgos, los cuales tendrán la responsabilidad de aprobar procesos, políticas y estrategias para la mitigación de cada riesgo presentado.

Con ello podemos listar los riesgos actuales que se presentan en cada proceso de la cooperativa y el riesgo que supone cada uno de ellos en la siguiente figura.

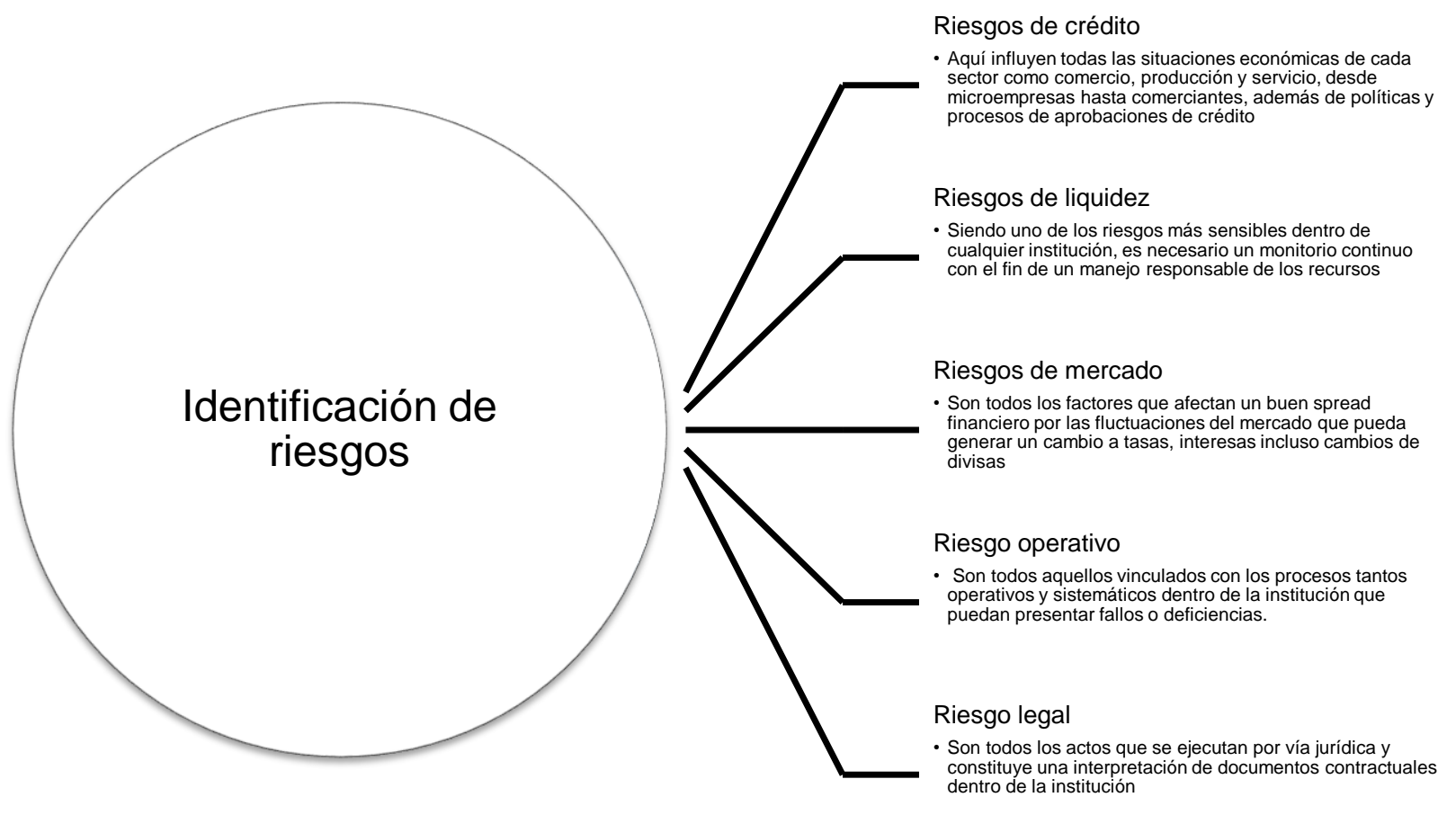

Figura 4. Identificación de riesgos.

Fuente: Los autores. 
CIENCIAMATRIA

Revista Interdisciplinaria de Humanidades, Educación, Ciencia y Tecnología

Año VII. Vol. VII. N¹2. Enero - Junio. 2021

Hecho el depósito de ley: pp201602FA4721

ISSN-L: 2542-3029; ISSN: 2610-802X

Universidad Nacional Experimental Francisco de Miranda (UNEFM). Santa Ana de Coro. Venezuela

Edgar Fernando Arévalo-Jara; Mariella Johanna Jácome-Ortega;

Cristián Andrés Erazo-Álvarez

\section{Analizar y priorizar}

En este punto se considera la clasificación previa de los riesgos dentro de la cooperativa, a ello hay que sumar que el ente regulador SEPS propone un análisis de los riesgos según su impacto y probabilidad ya sea este bajo, medio o alto, en este punto también se fundamenta un principio de todo ente financiero y más dentro de la Cooperativa CAJA, que son los eventos o riegos que produzcan perdidas económicas, para ello se analizan los 5 riesgos y cuáles son los eventos que generen mayor impacto, se aplica una matriz de riesgos con la finalidad tomar estrategias para mitigarlos.

\section{Matriz de riesgos}

\begin{tabular}{|c|c|c|c|c|}
\hline & $\begin{array}{c}\text { Probabilid } \\
\text { ad }\end{array}$ & $\begin{array}{c}\text { Graveda } \\
d\end{array}$ & $\begin{array}{l}\text { Valor } \\
\text { del }\end{array}$ & $\begin{array}{l}\text { Nivel de } \\
\text { Riesgo }\end{array}$ \\
\hline \multicolumn{5}{|l|}{ Riesgo de crédito } \\
\hline Incumplimiento a políticas & 4 & 5 & 20 & Muy grave \\
\hline $\begin{array}{l}\text { Desconocimiento de sectores } \\
\text { vulnerables }\end{array}$ & 3 & 3 & 9 & Importante \\
\hline $\begin{array}{l}\text { Falta de procesos para la concesión } \\
\text { de créditos }\end{array}$ & 3 & 3 & 9 & Importante \\
\hline $\begin{array}{l}\text { Información errónea de los } \\
\text { asociados }\end{array}$ & 2 & 2 & 4 & Apreciable \\
\hline & $\begin{array}{l}\text { Probabilidad } \\
\text { (Ocurrencia) }\end{array}$ & $\begin{array}{l}\text { Gravedad } \\
\text { (Impacto) }\end{array}$ & $\begin{array}{l}\text { Valor } \\
\text { del }\end{array}$ & $\begin{array}{l}\text { Nivel de } \\
\text { Riesgo }\end{array}$ \\
\hline
\end{tabular}

\begin{tabular}{|c|c|c|c|c|}
\hline Falta de fondos disponibles & 3 & 5 & 15 & Muy grave \\
\hline Manejo inadecuado de sobre tasas & 4 & 3 & 12 & Importante \\
\hline Fuga de depósitos a corto plazo & 3 & 3 & 9 & Importante \\
\hline Falta de financiación externa & 2 & 1 & 2 & Marginal \\
\hline
\end{tabular}


CIENCIAMATRIA

Revista Interdisciplinaria de Humanidades, Educación, Ciencia y Tecnología

Año VII. Vol. VII. N¹2. Enero - Junio. 2021

Hecho el depósito de ley: pp201602FA4721

ISSN-L: 2542-3029; ISSN: 2610-802X

Universidad Nacional Experimental Francisco de Miranda (UNEFM). Santa Ana de Coro. Venezuela

Edgar Fernando Arévalo-Jara; Mariella Johanna Jácome-Ortega;

Cristián Andrés Erazo-Álvarez

Riesgo de mercado

\begin{tabular}{|c|c|c|c|}
\hline $\begin{array}{l}\text { Probabilidad } \\
\text { (Ocurrencia) }\end{array}$ & $\begin{array}{l}\text { Gravedad } \\
\text { (Impacto) }\end{array}$ & $\begin{array}{c}\text { Valor } \\
\text { del }\end{array}$ & $\begin{array}{c}\text { Nivel de } \\
\text { Riesgo }\end{array}$ \\
\hline
\end{tabular}

\begin{tabular}{|c|c|c|c|c|}
\hline $\begin{array}{c}\text { Variaciones económicas del país } \\
\text { con respecto a la moneda }\end{array}$ & 3 & 5 & 15 & Muy grave \\
\hline $\begin{array}{c}\text { Cambios en la tasas activas y } \\
\text { pasivas }\end{array}$ & 3 & 4 & 12 & Importante \\
\hline Deterioro a la imagen institucional & 2 & 5 & 10 & Importante \\
\hline Devaluó de los activos & 2 & 1 & 2 & Marginal \\
\hline \multirow{2}{*}{ Riong } & $\begin{array}{c}\text { Probabilidad } \\
\text { (Ocurrencia) }\end{array}$ & $\begin{array}{c}\text { Gravedad } \\
\text { (Impacto) }\end{array}$ & $\begin{array}{c}\text { Valor } \\
\text { del }\end{array}$ & $\begin{array}{c}\text { Nivel de } \\
\text { Riesgo }\end{array}$ \\
\hline
\end{tabular}

Riesgo de operativo

\begin{tabular}{|c|c|c|c|l|}
\hline Procesos no establecidos y definidos & 4 & 5 & 20 & Muy grave \\
\hline $\begin{array}{c}\text { Personal inadecuado en áreas } \\
\text { estratégicas }\end{array}$ & 4 & 2 & 8 & Apreciable \\
\hline Fallas en el área de TI & 3 & 2 & 6 & Apreciable \\
\hline $\begin{array}{c}\text { Inadecuada respuesta a factores } \\
\text { externos }\end{array}$ & 2 & 1 & 2 & Marginal \\
\hline & $\begin{array}{c}\text { Probabilidad } \\
\text { (Ocurrencia) }\end{array}$ & $\begin{array}{c}\text { Gravedad } \\
\text { (Impacto) }\end{array}$ & $\begin{array}{c}\text { Valor } \\
\text { del }\end{array}$ & $\begin{array}{c}\text { Nivel de } \\
\text { Riesgo }\end{array}$ \\
\hline
\end{tabular}

Riesgo de legal

\begin{tabular}{|c|c|c|c|l|}
\hline $\begin{array}{c}\text { Incumplimiento legal y normativo } \\
\text { SEPS }\end{array}$ & 4 & 5 & 20 & Muy grave \\
\hline $\begin{array}{c}\text { Documentación contractual } \\
\text { inadecuada }\end{array}$ & 3 & 5 & 15 & Muy grave \\
\hline $\begin{array}{c}\text { Procesos deficientes para un normal } \\
\text { giro financiero }\end{array}$ & 2 & 4 & 8 & Apreciable \\
\hline Fallas en los actos societarios & 1 & 1 & 1 & Marginal \\
\hline
\end{tabular}




\section{CIENCIAMATRIA}

Revista Interdisciplinaria de Humanidades, Educación, Ciencia y Tecnología

Año VII. Vol. VII. N¹2. Enero - Junio. 2021

Hecho el depósito de ley: pp201602FA4721 ISSN-L: 2542-3029; ISSN: 2610-802X

Universidad Nacional Experimental Francisco de Miranda (UNEFM). Santa Ana de Coro. Venezuela

Edgar Fernando Arévalo-Jara; Mariella Johanna Jácome-Ortega;

Cristián Andrés Erazo-Álvarez

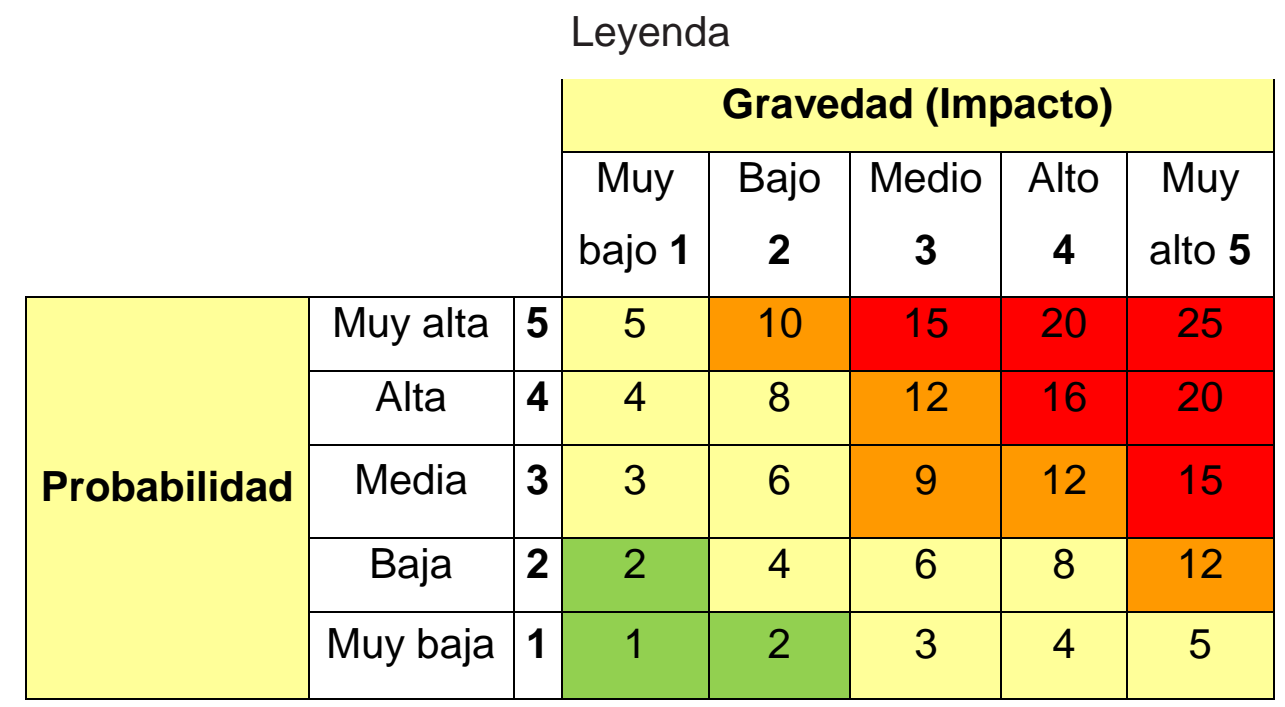

Figura 5. Matriz de riesgos.

Fuente: Recio (2009).

Como se puede evidenciar cada evento puede tener un impacto diferente y su priorización se basa en las perdidas económicas que puede generar dicho evento, por ejemplo, en el riesgo operativo su probabilidad y su impacto pueden ser muy graves, pero son eventos que a pesar de que requieren medidas preventivas urgentes pueden tener un impacto económico muy bajo por lo que su gestión se aplazaría para controlar fuertemente otros que afectarían a mayor escala en la institución.

Con ello la priorización se establece en la siguiente figura con el fin de generar estrategias para un control y evaluación de los mismos: 


\section{CIENCIAMATRIA}

Revista Interdisciplinaria de Humanidades, Educación, Ciencia y Tecnología

Año VII. Vol. VII. N¹2. Enero - Junio. 2021

Hecho el depósito de ley: pp201602FA4721

ISSN-L: 2542-3029; ISSN: 2610-802X

Universidad Nacional Experimental Francisco de Miranda (UNEFM). Santa Ana de Coro. Venezuela

Edgar Fernando Arévalo-Jara; Mariella Johanna Jácome-Ortega;

Cristián Andrés Erazo-Álvarez

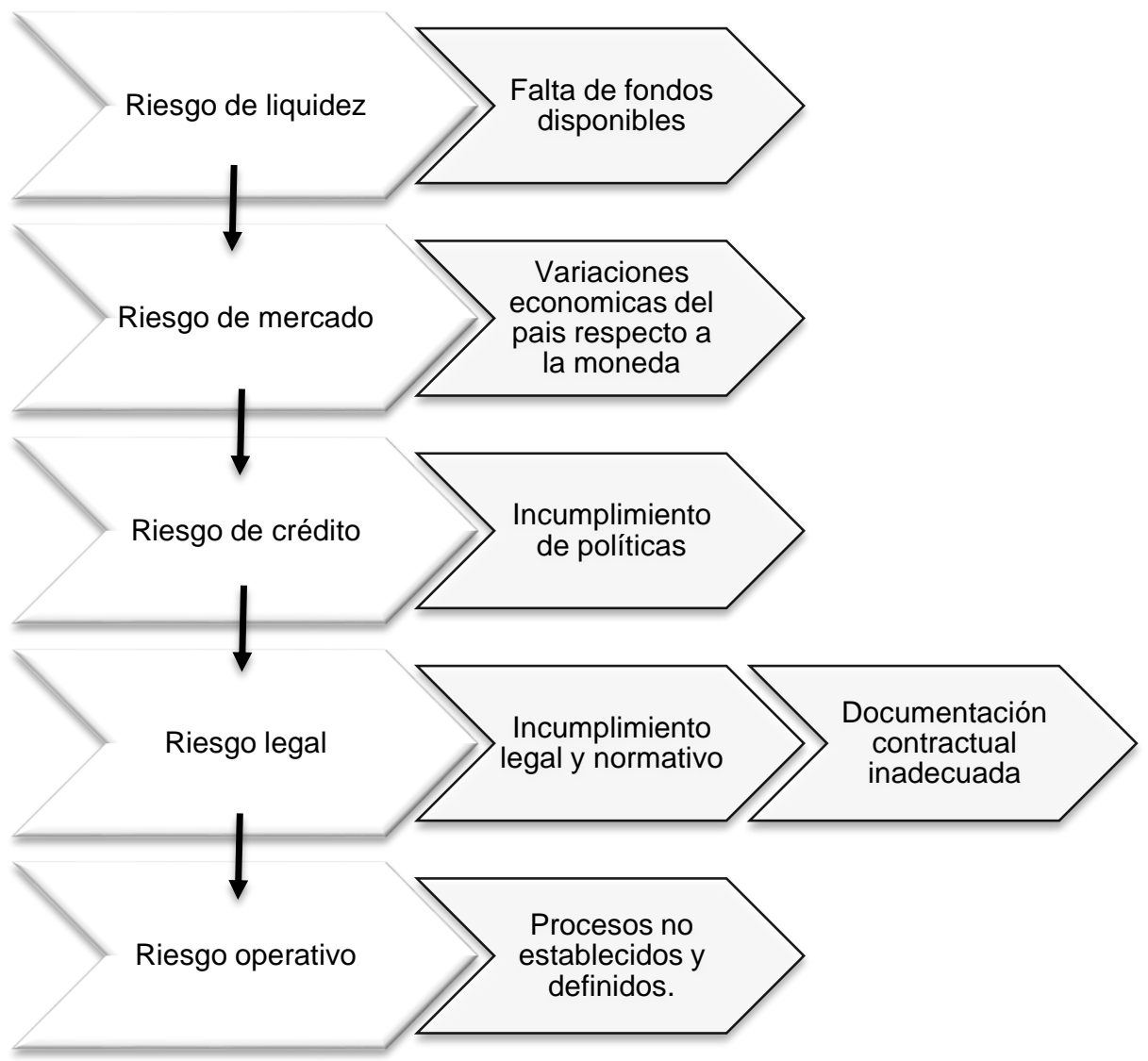

Figura 6. Tabla de prioridad del riesgo.

Fuente: Los autores.

\section{Control, evaluación y mitigación}

Con la finalidad de una mitigación óptima de los riesgos, la cooperativa siempre optara por estrategias ya sean cuantitativas o cualitativas, para ello se propone una optimización de las estrategias, con la implementación de la distancia relativa de Hamming, con el fin de aumentar la eficacia del control y evaluación para determinar un accionar que genere una mitigación de cada riesgo, para esto se considera la apreciación de los expertos que nos proyectó la metodología de la encuesta y con ello generar un aumento de calidad en cada uno de los procesos y generación de estrategias detalladas a continuación. 
CIENCIAMATRIA

Revista Interdisciplinaria de Humanidades, Educación, Ciencia y Tecnología

Año VII. Vol. VII. N¹2. Enero - Junio. 2021

Hecho el depósito de ley: pp201602FA4721

ISSN-L: 2542-3029; ISSN: 2610-802X

Universidad Nacional Experimental Francisco de Miranda (UNEFM). Santa Ana de Coro. Venezuela

Edgar Fernando Arévalo-Jara; Mariella Johanna Jácome-Ortega;

Cristián Andrés Erazo-Álvarez

\section{Tabla 2.}

Estrategias para un óptimo control y evaluación.

\begin{tabular}{|l|l|}
\hline Estrategias de monitoreo & $\begin{array}{l}\text { Gestiones de monitoreo en todos los } \\
\text { riesgos presentados y aplicación de } \\
\text { indicadores financieros con niveles de } \\
\text { impacto en óptimos tolerables y críticos } \\
\text { Aplicación de procesos acoplados a TI } \\
\text { para una mejor respuesta a cada evento } \\
\text { de riesgo }\end{array}$ \\
\hline Estrategias de acciones & $\begin{array}{l}\text { Generación de ideas en estado inicial y } \\
\text { planificación de cada gestión para un } \\
\text { análisis desde todos los ángulos posibles } \\
\text { de los riesgos con resultados a largo plazo }\end{array}$ \\
\hline
\end{tabular}

A partir de eso se realizó una evaluación para las estrategias planteadas y con el fin de llegar a las estrategias óptimas se aplicó distancia relativa de Hamming con una obtención de los siguientes resultados en la siguiente figura:

\section{Distancia Relativa de Hamming}

\begin{tabular}{|c|c|c|c|c|c|}
\hline \multirow{2}{*}{ Variables } & $\begin{array}{c}\mathbf{R C =} \\
\text { Riesgo } \\
\text { de } \\
\text { crédito }\end{array}$ & $\begin{array}{c}\text { RDL= } \\
\text { Riesgo } \\
\text { de } \\
\text { liquidez }\end{array}$ & $\begin{array}{c}\mathbf{R M =} \\
\text { Riesgo de } \\
\text { mercado }\end{array}$ & $\begin{array}{c}\mathbf{R O =} \\
\text { Riesgo } \\
\text { operativo }\end{array}$ & $\begin{array}{c}\mathbf{R L}= \\
\text { Riesgo } \\
\text { legal }\end{array}$ \\
\hline \multirow{2}{*}{$\mathrm{I}=$} & $\mathbf{R C}$ & $\mathbf{R D L}$ & $\mathbf{R M}$ & $\mathbf{R O}$ & $\mathbf{R L}$ \\
\cline { 2 - 6 } & 0,9 & 0,8 & 0,8 & 0,7 & 0,7 \\
\hline
\end{tabular}

\begin{tabular}{l|l|l|l|l|l|} 
Monitoreo & 0,4 & 0,9 & 0,8 & 0,3 & 0,4 \\
\cline { 2 - 5 }
\end{tabular}


CIENCIAMATRIA

Revista Interdisciplinaria de Humanidades, Educación, Ciencia y Tecnología

Año VII. Vol. VII. N¹2. Enero - Junio. 2021

Hecho el depósito de ley: pp201602FA4721

ISSN-L: 2542-3029; ISSN: 2610-802X

Universidad Nacional Experimental Francisco de Miranda (UNEFM). Santa Ana de Coro. Venezuela

Edgar Fernando Arévalo-Jara; Mariella Johanna Jácome-Ortega;

Cristián Andrés Erazo-Álvarez

\begin{tabular}{|l|l|l|l|l|}
\hline 0,5 & 1 & 0 & 0,4 & 0,3 \\
\hline \multicolumn{5}{c}{5} \\
\hline
\end{tabular}

0,4400

\begin{tabular}{|c|c|c|c|c|c|}
\hline E2= & RC & RDL & RM & RO & RL \\
\hline \multirow{2}{*}{ Acciones } & 0,9 & 0,7 & 0,6 & 0,9 & 0,9 \\
\cline { 2 - 6 } & & &
\end{tabular}

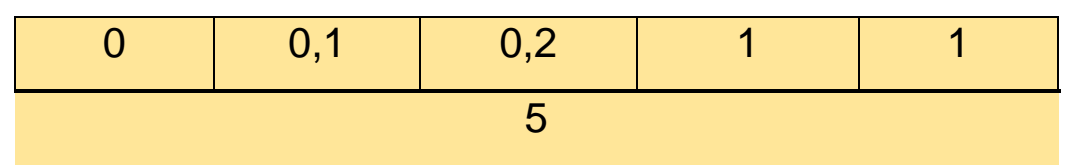

0,4600

\begin{tabular}{|r|c|c|c|c|c|}
\hline E3= & RC & RDL & RM & RO & RL \\
\hline Planificación & 1 & 0,9 & 0,8 & 0,8 & 0,7 \\
\cline { 2 - 6 } & & &
\end{tabular}

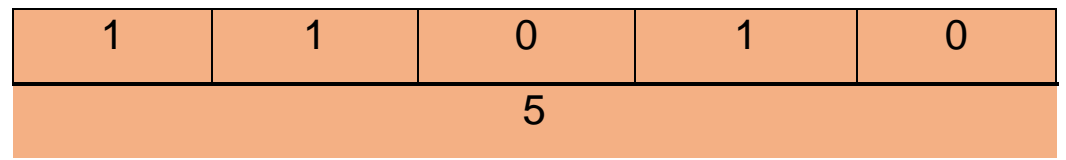

0,6000

Figura 6. Elaboración distancia relativa de Hamming.

Fuente: Los autores.

Como resultado tenemos que todas las estrategias que estén en planificación son las mejores para una mitigación óptima de los riegos ya que son las que mejor se adecuan a lo ideal por su aproximación a uno, de este modo todos los departamentos, procesos y gestiones presentaran soluciones óptimas a largo y corto plazo. También se debe considerar que todo el proceso exige un monitoreo y constante comunicación la cual nos aportara nuevas acciones y visiones de los posibles riesgos que se encuentran expuesta la Cooperativa Caja. 


\section{CIENCIAMATRIA \\ Revista Interdisciplinaria de Humanidades, Educación, Ciencia y Tecnología \\ Año VII. Vol. VII. N¹2. Enero - Junio. 2021 \\ Hecho el depósito de ley: pp201602FA4721 \\ ISSN-L: 2542-3029; ISSN: 2610-802X \\ Universidad Nacional Experimental Francisco de Miranda (UNEFM). Santa Ana de Coro. Venezuela}

Edgar Fernando Arévalo-Jara; Mariella Johanna Jácome-Ortega;

Cristián Andrés Erazo-Álvarez

\section{CONCLUSIONES}

Encontrar la mejor estrategia para mitigar los riesgos, resulta un hito en el ámbito financiero y cooperativo, ya que al identificar estos riesgos con antelación se podría mitigarlos antes que se conviertan en un problema profundo y aplicando una verdadera administración de riesgos se innovará cada una de sus áreas, permitiendo así un desarrollo efectivo de la entidad.

Con el objetivo de reducir los diferentes tipos de riesgos se plateo esta investigación de tipo aplicativo, buscando así tener un nivel de control alto sobre los riesgos presentes, y mediante las estrategias planteadas evitar situaciones que puedan generar no solo perdidas económicas sino hasta el cese de actividades de cada institución.

La aplicación de la metodología de la distancia relativa de Hammig nos aportó información objetiva para tomar decisiones sobre las estrategias en base a cada riesgo, otorgándonos una visión más amplia para saber cuáles son las alternativas a considerar y que se acerque lo que consideran los expertos como ideal para esta área.

\section{REFERENCIAS CONSULTADAS}

Anguita, C., Labrador, R., \& Campos, D. (2003). La encuesta como técnica de investigación. Elaboración de cuestionarios y tratamiento estadístico de los datos [The survey as a research technique. Elaboration of questionnaires and statistical treatment of the data]. Aten Primaria, 153. Obtenido de https://cutt.ly/2g1tS5c

Bolaño-Rodríguez, Y, Alfonso-Robaina, D, Pérez-Barnés, A, \& Arias-Pérez, M. (2014). Modelo de Dirección Estratégica basado en la Administración de Riesgos. Ingeniería Industrial, 35(3), 344-357.

Bueno, G., Correa, C., \& Echeverry, J. (2010). Administración de riesgos una visión global y moderna. Universidad de la República. Obtenido de https://cutt.ly/6gNz3Wm

Carrión-Agila, E. A., Erazo-Álvarez, J. C., Narváez-Zurita, C. I., \& Trelles-Vicuña, D. F. (2019). La lógica difusa como herramienta para la evaluación del desempeño de los servidores públicos. CIENCIAMATRIA, 5(1), 215-244. https://doi.org/10.35381/cm.v5i1.265 
Cooperativa CAJA. (2018). Manual de administración integral de riesgos [Comprehensive Risk Management Manual]. Cuenca: Cooperativa Caja.

Cuello-Lascano, R., Pallares-Caro, L., \& Wehdeking-Arcieri, E. (2008). Aplicación del Estándar Australiano de Administración del Riesgo AS/NZS 4360:1999 en la empresa GECELCA. Pensamiento \& Gestión, (25),94-112.

De Lara Haro, A. (2005). Medición y control de riesgos financieros [Measurement and control of financial risks]. México: Editorial Limusa, S.A de C.V. Grupo Noriega Editores.

Echemendía-Tocabens, B. (2011). Definiciones acerca del riesgo y sus implicaciones. Revista Cubana de Higiene y Epidemiología, 49(3), 470-481.

Estándar Australiano de Administración del Riesgo AS/NZS 4360:1999.

Estupiñán-Gaitán, R. (2015). Administración de riesgos E.R.M. y la auditoría interna. En R. E. Gaitán, Administración de riesgos E.R.M. y la auditoría interna (pág. 384). Bogotá: Ecoe Ediciones.

Heredia-González, D. (2015). Administración de riesgos [Risk Management]. UNAM Dirección general de bibliotecas. Obtenido de https://cutt.ly/7hhgrYl

Mejía-Caguasango, K. (2017). Cooperativas cómo funcionan y los tipos [Cooperatives how they work and the types]. Obtenido de https://cutt.ly/ogNvioM

Mejía-Quijano, R. (2006). Administración de riesgos: un enfoque empresarial. Medellín, Colombia: Fondo Editorial Universidad EAFIT.

Recio, M. (2009). Haciendo tus proyectos realidad [Making your projects a reality]. En M. Recio, Innovación empresarial INNOVATIA (p. 41). Madrid: Ide-Cesem. Obtenido de https://cutt.ly/XhgZBUZ

Rojas, F. (2002). Gestión de riesgos en la organización. Revista de la Facultad de Ciencias Económicas: Investigación y Reflexión, X(2),18-38.

Soler, R., Martínez, L., \& Oñate, A. (2016). Competencia en la incertidumbre. Caso de estudio: Docentes de la Escuela de Ingeniería de Empresa. Universidad $Y$ Sociedad, 8(1). 


\section{CIENCIAMATRIA}

Revista Interdisciplinaria de Humanidades, Educación, Ciencia y Tecnología

Año VII. Vol. VII. N¹2. Enero - Junio. 2021

Hecho el depósito de ley: pp201602FA4721

ISSN-L: 2542-3029; ISSN: 2610-802X

Universidad Nacional Experimental Francisco de Miranda (UNEFM). Santa Ana de Coro. Venezuela

Edgar Fernando Arévalo-Jara; Mariella Johanna Jácome-Ortega;

Cristián Andrés Erazo-Álvarez

Thompson, I. (2006). Definición de Encuesta [Survey Definition]. https://cutt.ly/cg1rHCv

(C2021 por los autores. Este artículo es de acceso abierto y distribuido según los términos y condiciones de la licencia Creative Commons Atribución-NoComercial-Compartirlgual 4.0 Internacional (CC BY-NC-SA 4.0) (https://creativecommons.org/licenses/by-nc-sa/4.0/). 